\title{
Strengthening Co-Teaching Partnerships for High Productivity
}

\author{
${ }^{1}$ Lynne Harper Mainzer, ${ }^{1}$ Jacqueline A. Nunn, ${ }^{2}$ Annette Bautz, ${ }^{3}$ Richard W. Mainzer Jr. \\ ${ }^{1}$ Johns Hopkins University, ${ }^{2}$ Consultant, ${ }^{3}$ Mainzer Consulting Services \\ ${ }^{1}$ Center for Technology in Education \\ ${ }^{1}$ Columbia, ${ }^{3}$ Alexandria, Virginia
}

\begin{abstract}
Two teachers sharing space in a single classroom does not guarantee that they will function as an effective team. Recent research findings related to the efficacy of co-teaching indicate the need for more professional development to support teachers in building collaborative competence along with clear co-teaching roles and goals. So, how does a co-teaching team develop the mutual trust, respect, and support needed to create and to sustain an inclusive classroom? This article will describe how a structured, teambuilding protocol that is specifically designed to strengthen co-teaching partnerships helps general and special educators effectively collaborate and co-instruct. The step-bystep guide, called UNITED ${ }^{\odot}$, provides the scaffolding to promote co-teaching partnerships that produce positive outcomes for students with disabilities in general education learning settings.
\end{abstract}

\section{Introduction}

As expectations for more collaboration continue to increase within educational systems, the utilization of professional teams within schools expands and intensifies. No matter the purpose of professional teams, it is important that they are structured for productivity and high performance if they are expected to generate innovative ideas, make high quality decisions, implement interventions effectively, and promote student learning. One, prominent type of professional team-the coteaching partnership-emerged as an inclusion model in the early 1980s. In co-teaching, general and special educators collaboratively plan, coinstruct, and co-assess so that students with disabilities access general education curriculum and reach or exceed proficiency on specified learning targets and content standards.

\section{Co-teaching in Review}

Over the past thirty years, these professional teaching teams have produced positive outcomes for scores of students. In fact, several quantitative research studies of students with learning disabilities reported considerable gains in achievement. According to one study, students assigned to classrooms that were co-taught improved substantially in reading achievement [1]. Likewise, improved math scores were demonstrated by middle school students with learning disabilities as compared with their counterparts in traditional classrooms [2]. Moreover, co-teaching appears to be a successful alternative to the conventional resource room or "pull out" support structure [3]. Studies of these specialized "pull out" programs, which are designed to provide assistance for students with disabilities, students who are bilingual, or those from low-income households, concluded that these programs often fail to provide the support necessary to produce benefits for special student populations [4]. With these types of unsatisfactory results, it is no surprise that school leaders turn to co-teaching as a viable option for teaching students with special learning needs.

Although these studies point to the positive results of co-teaching, other quantitative studies report contradictory findings. Several quantitative studies dismiss co-teaching benefits, as they show that achievement levels of students with disabilities in co-taught classrooms did not improve [5], and that declining test scores were realized in some coteaching environments [6]. Other research failed to quantify positive impacts of co-teaching on student behavior, student engagement, teacher availability, and access to differentiated instruction [7].

Similar to quantitative studies that examine coteaching partnerships, qualitative results (i.e., involving case studies, anecdotal reports, and surveys) examining perceptions, satisfaction levels, 
and attitudes of co-teachers offer equivocal results. First, a number of qualitative studies reveal a convincing degree of teacher and administrator satisfaction with the general outcomes of coteaching, as shown in the study where teachers perceived co-teaching as providing benefits to all students [8]. Additional studies indicate that teachers valued the collaboration afforded by co-teaching [9] and that they perceived their instructional skills improved as a result of the co-teaching experience [10].

While these studies reflect positive attitudes toward co-teaching, other findings suggest less optimistic points of view. When studies report negative teacher perceptions of co-teaching, the findings most often reflect shortcomings in implementation and insufficient planning time [11]. Teachers cite lack of adequate professional development as one of the major obstacles to developing successful collaborative relationships [12]. Studies suggest that implementation failures include the lack of preparatory training to build strong co-teacher skills, clarify roles, instill mutual respect, and establish meaningful goals. It is noteworthy that teachers, who have been in coteaching relationships, strongly agree that co-teacher compatibility is a critical prerequisite for success [13].

The studies cited above suggest that teachers value effective professional development prior to beginning a co-teaching assignment. If, in fact, coteaching partnerships are "jump started" with professional development to specifically build strong collaborative relationships, compatibility, and shared goals, it may be conjectured that the number of quantified successes of co-teaching would increase. Thus, the quantitative results cited earlier regarding the lack of student progress in co-teaching settings might be due to poor implementation rather than limitations of the co-teaching team model. In this regard, failure to measure quantitative academic gains may be directly related to insufficient professional development to build high performance co-teaching partnerships. In too many instances, these teaching partnerships are configured due to position title rather than competency level and often lack the necessary tools and training to build strong, highly productive co-teaching partnerships [14].

\section{A Complex Relationship}

As suggested by the research, the relationship between general and special educators is complex. General educators focus on teaching students as a group to acquire knowledge and skills and special educators target individual students to accommodate learning needs. Co-teaching partnerships have to merge these different perspectives into a cohesive approach that addresses the challenging purpose of advancing learning among all students in the learning community, including students with disabilities. Consequently, for these partnerships to be highly effective and not just two teachers sharing a classroom, they need to develop a shared mission, mutual goals, and specific roles and responsibilities to carry out during instruction. Importantly, administrative support is essential so that time is allocated for co-teachers to practice and build expertise in working as a well-coordinated partnership capable of putting strategies and tools in action to realize their shared purpose and goals.

\section{Building High Performance Co- Teaching Partnerships}

The collaboration between a general educator and a special educator, who are co-responsible for establishing a positive and productive learning environment for diverse students, creates a distinctively unique professional partnership. Characteristically, co-teaching unites two sets of skills, personalities, and attributes. It is a united partnership that brings together two belief systems and two routines for the planning, executing, and managing of classroom instruction.

To be sure, successful co-teaching doesn't happen by chance. Nor should it be left primarily to relationships based solely on likeability and personal friendships. Co-teaching is not unlike a corporate merger. It requires a strategic, structured approach to reorganize procedural methodologies, to reengineer roles, and to generate clear, shared goals.

This structured process applied to co-teaching is reflected within a defined protocol, called UNITED ${ }^{\odot}$ (see Figure 1), that specifically supports the development and productivity of the co-teaching teams. The UNITED ${ }^{\odot}$ protocol consists of six steps that address important elements of co-teaching through team-building activities and exercises. The UNITED $^{\odot}$ protocol seeks to establish professional and personal compatibility, beginning with development of shared values.

Studies repeatedly indicate that successful coteaching requires the direct communication of beliefs, philosophies, principles, and goals between participants [15]. The UNITED ${ }^{\odot}$ protocol unites two professionals initially at an intrinsic level. Building on this intrinsic foundation, co-teaching teams develop practical interventions and sound logistics to attain instructional goals. With specific guidelines 
included in each of the six steps, the intent of the protocol is to:

1. Produce cohesive teaching partnerships that build positive inclusive learning environments;

2. Prepare instructional plans to continuously improve the management and delivery of classroom instruction; and

3. Provide differentiated instruction and effective learning for all students, particularly students with disabilities.

\begin{tabular}{|ll|}
\hline \multicolumn{2}{|c|}{ UNITED $^{\odot}$} \\
\hline $\mathbf{U}$ & Unveil beliefs, visions, \& mission \\
\hline $\mathbf{N}$ & Name operating standards \\
\hline $\mathbf{I}$ & Identify teaming principles \\
\hline $\mathbf{T}$ & Target goals \& roles \\
\hline $\mathbf{E}$ & Establish team identity \\
\hline $\begin{array}{l}\text { D } \\
\text { together }\end{array}$ & Determine logistics for working \\
\hline
\end{tabular}

Figure 1. UNITED ${ }^{\circ}$

\subsection{Unveil Beliefs, Vision, and Mission}

Conflicting beliefs regarding instruction, student-teacher interaction, and behavioral management have been shown to result in less effective co-teaching [16]. In the first step of the UNITED $^{\odot}$ protocol each teacher in the co-teaching partnership reveals his/her values and views. This is an opportunity to openly share without scrutinizing or judging. This does not presume that the members of a co-teaching team adopt identical beliefs, but rather that they better understand their beliefs and those of their co-teaching partner. Through structured sessions and reinforcement activities, teachers disclose to each other their individual beliefs about teaching and learning (e.g., instructional practices, shared instruction, classroom management, instructional grouping, etc.) and discuss any differences.

Following the disclosure of individual beliefs, teachers then ascertain their common (or shared) beliefs about teaching and learning, which leads to the emergence of a jointly developed vision statement. The vision statement describes what the co-teaching partnership will accomplish and what significant difference the team will make. A vision statement, alludes to the potential of the co-teaching team, for example: "Our vision is a smoothly operating co-teaching partnership that can build engaging, technology-rich learning environments in which all students, including students with disabilities, can be successfully prepared to meet the challenges of the $21^{\text {st }}$ century workplace."

A mission statement puts the vision into practice by stating the specific actions needed to realize the vision. A mission statement is an operational definition of the vision and includes observable activities such as ". . . students with disabilities will access the general education curriculum, attain IEP goals, and reach state performance standards. . "

\subsection{Name Operating Standards}

As suggested by the findings of various studies, there is wide variability in the implementation of coteaching [17]. UNITED ${ }^{\odot}$ addresses this issue by instilling a firm awareness of a core set of standards (see Figure 2.). The standards guide the day-to-day operation of co-teaching partnerships. Each coteacher is responsible for embracing the operating standards and for putting them into practice to enhance work efficiency of the team.

CO-TEACHING OPERATING STANDARDS
Listen to understand
Complete activities on time
Participate and contribute to the team
Be respectful
Offer help willingly
Stay organized and prepared

Figure 2. Co-Teaching standards

\subsection{Identify High-Performance Teaming Principles}

The literature in cooperative learning and in corporate quality initiatives emphasizes a strong commitment to productive, synergistic teamwork [18]. The teaming principles of UNITED ${ }^{\odot}$ solidify the mission and ensure that the partnership continues to function at its highest level. An effective coteaching team operates from a set of principles, or behaviors, that guide the team to meet the team's vision and mission. Teachers commit to employ the following high-performance teaming principles:

a. Positive interdependence: recognizing the coexistence of goals and roles to ensure 
an equal status partnership and cooperation.

b. Individual accountability: each teacher is accountable for doing his/her share of the work to accomplish the mission.

c. Performance monitoring: teachers regularly assess how well they are working together and make decisions regarding modifications as needed.

d. Engagement and momentum: teacher interaction is frequent and goal-focused with a sense of enthusiasm and a willingness to preserve momentum.

e. Collaborative competence: teams use effective communication skills that enable confidence, cooperation, and problem solving and conflict management.

f. Technology optimization: each teacher is committed to advancing his/her skills and to using a full spectrum of administrative and instructional technologies.

Through the team-based activities of UNITED ${ }^{\odot}$, teachers discuss the manner(s) in which they will employ the principles and commit to incorporating them into their classroom. Periodic review of principles guides the co-teaching partnership to practice continuous improvement and to work at its highest level of productivity.

\section{4. Target Goals and Roles}

Goals operationally define the daily classroom activities that will fulfill the mission of the coteaching team. These are short-term goals, to be accomplished at predetermined intervals (e.g., every quarter or marking period). Professional development activities of UNITED $\odot$ guide coteaching teams to develop "SMART" goals (see Figure 3.) [19].

Regularly monitoring the progress of coteaching goals exercises the teaming principles of positive interdependence and individual accountability. Goals are derived from data and focus on areas in need of improvement or modification for students and/or the co-teaching partners. Using the teaming principle of performance monitoring, performance data is analyzed to support movement toward the vision and mission. Examples of SMART co-teaching goals are:

- "By November 3, 2014, we will co-plan instructional activities weekly that incorporate technology, as measured by the types of technologies in the lesson plans."

- "By February 3, 2014, we will use three cooperative learning strategies for story re-telling to improve reading comprehension for students with disabilities in reading/language arts, as measured by the second quarter assessment test."

\begin{tabular}{|l|l|}
\hline \multicolumn{2}{|c|}{ SMART GOALS } \\
\hline Specific & $\begin{array}{l}\text { Define outcome; who, } \\
\text { what, where }\end{array}$ \\
\hline Measureable & $\begin{array}{l}\text { Identify data to assess } \\
\text { outcome }\end{array}$ \\
\hline Attainable & Plan for realistic outcomes \\
\hline Results-oriented & $\begin{array}{l}\text { Align outcome with long } \\
\text { range objectives }\end{array}$ \\
\hline Time-bound & $\begin{array}{l}\text { Select clear, manageable } \\
\text { timelines }\end{array}$ \\
\hline
\end{tabular}

Figure 3. SMART Goals

Roles of individual teachers in each partnership are different; yet it is essential that parity exist in the roles and responsibilities of each teacher [20]. The general educator and the special educator both must have a fundamental understanding of the curriculum and of student learning. Additionally, the role of each co-teacher differs when addressing specific areas such as specific content knowledge, curriculum standards, differentiated instruction, behavior management, instructional technologies, accommodations for students with disabilities, interaction with parents, and involvement with the school community.

\subsection{Establish the Co-Teaching Team Identity}

As the members of co-teacher teams discover commonalities and appreciate their individual differences, a shared identity evolves. During professional development, co-teaching partnerships proceed through team-based activities, from which evolve the creation of an image reflecting the strengths of their partnership and their co-teaching mission. Teachers are encouraged to create an outward sign, which may include a team name and/or logo. Sharing the team identity with students and with the school environment fosters a sense of cohesiveness and camaraderie to the class as well as to the co-teaching unit. A strong team identity 
cultivates a commitment toward attaining team goals and strengthens productivity.

\subsection{Determine Logistics for Working Together}

The final step of the UNITED $^{\odot}$ protocol is developing a dynamic logistics plan (Figure, 4). Ongoing communication regarding the orchestration of classroom activities enhances teacher competency to work as a team, expediting the flow of information and resources to effectively meet goals. Logistical planning creates a functional routine to maximize resourcefulness, organization, proficiency, and effective decision-making.

A structured logistics plan enables teachers, in a co-teaching partnership, to balance the tactical details of classroom organization, daily instruction, behavior management, and assessment while progressing toward goal attainment. Co-teaching logistics include: space organization, resource coordination, meeting plans, behavior management, grading, participation in electronic learning communities, IEP goals, etc. Questions are included within each of these topic areas to prompt productive discussion and decision making on important tasks and division of roles and responsibilities.

\begin{tabular}{|l|l|}
\hline \multicolumn{2}{|c|}{ ADMINISTRATIVE TASKS } \\
\hline YES & $\begin{array}{l}\text { Has it been determined how } \\
\text { parent conferences will be } \\
\text { managed? }\end{array}$ \\
\hline YES & $\begin{array}{l}\text { Has it been determined how } \\
\text { communication with parents will } \\
\text { be managed? }\end{array}$ \\
\hline YES & $\begin{array}{l}\text { Is emergency information } \\
\text { available to both teachers? }\end{array}$ \\
\hline NO
\end{tabular}

\begin{tabular}{|l|c|}
\hline & ROLES \\
\hline $\begin{array}{l}\text { Who monitors } \\
\text { special scheduling } \\
\text { needs of } \\
\text { students? }\end{array}$ & General Educator \\
\hline $\begin{array}{l}\text { Who attends IEP } \\
\text { meetings? }\end{array}$ & General Educator \\
\hline $\begin{array}{l}\text { Who attends } \\
\text { student support } \\
\text { meetings? }\end{array}$ & Special Educator \\
\hline
\end{tabular}

Figure 4. Excerpts: UNITED Logistics Plan ${ }^{\odot}$

\subsection{Qualitative Findings: UNITED ${ }^{\oplus}$}

In the spring of 2014, interviews of co-teaching teams and leaders in an urban setting were conducted to gain observations and perceptions from persons who have been directly involved with co-teaching and UNITED ${ }^{\odot}$ over several years. An interview was conducted with a lead training instructor for coteaching, who provides initial and ongoing professional development for multiple school districts. A second interview was conducted with the administrative supervisor of special education for a large urban school district, where co-teaching has been a standard practice for many years in response to mandates for the least restrictive environment (LRE).

Due to budgeting and scheduling constraints, not all co-teaching teams are acquainted with the UNITED $^{\odot}$ protocol prior to implementing a coteaching partnership. Both interviewees reported that co-teaching teams often receive training for the UNITED $^{\odot}$ protocol sometime after their co-teaching partnership began. While it is unfortunate that these co-teaching teams proceed without instruction on UNITED $^{\odot}$, the situation creates the existence of a sub-group of teachers, who did not receive the guidance of the UNITED ${ }^{\odot}$ protocol prior to beginning their co-teaching assignments.

The teachers in this subgroup are in the unique position to compare their participation in co-teaching with and without having instruction on the UNITED ${ }^{\odot}$ protocol. According to both interviewees, teachers, whose training on the UNITED $^{\odot}$ protocol was delayed, regarded the protocol as being highly valuable and a pivotal component in establishing successful compatibility. Teachers were quoted as saying, "Where has this been? I've been co-teaching without this valuable program!" and "I wish that every co-teaching partnership in the building can have this experience." The project manager observed that UNITED" ${ }^{\odot}$ has "turned some partnerships around . . . UNITED ${ }^{\odot}$ helps them understand their co-teaching partner."

The special education supervisor recounted similar experiences. Having observed the value of the UNITED ${ }^{\odot}$ protocol, the supervisor now ensures that professional development for all co-teaching teams initially includes the UNITED ${ }^{\odot}$ protocol, even if this requires that sessions be conducted prior to the opening of school in the fall.

Testimony from the administrator included the observation that, prior to the availability of the UNITED $^{\odot}$ protocol, teachers displayed "considerably more anxiety and trepidation" upon the launch of a co-teaching partnership. It was the opinion of the 
administrator that, through the $\mathrm{UNITED}^{\odot}$ protocol, teachers gained the comfort level and confidence to be a successful co-teaching partnership.

Based on observation, it was the opinion of the administrator that co-teaching partnerships, which receive training on the UNITED $^{\odot}$ protocol, demonstrate increased effectiveness and professional growth. As reported by the administrator, the typical scenario in co-teaching classrooms is one where two teachers alternately deliver substantive instruction and neither has the dominant role. Additionally, both teachers seem comfortable in working with small groups of students with learning disabilities. With the UNITED ${ }^{\odot}$ protocol "we're teaching them to be a strong team."

\section{Conclusion}

The UNITED ${ }^{\odot}$ Protocol offers the fundamental steps to create a strong foundation on which coteaching partnerships are built. Through the use of team-building activities and structured professional development, co-teaching partners:

- Understand and appreciate each other's beliefs and values,

- Cultivate mutual trust and generate a team identity,

- Develop and monitor instructional goals, and

- Attain instructional goals and perform as a high-performance team.

An effective teaching team comprised of a general and a special educator embodies the adage, "the whole is greater than the sum of the individual parts." Bringing the co-teaching team to a high level of productivity, professionalism, and performance requires that two teachers adopt one unified set of values, operating standards, principles, operational goals, and logistical strategies.

The objective of seamlessly blending the "parts" results in performance that surpasses that which each part could achieve independently. More inclusive and effective classrooms, led by highly capable coteaching partnerships, may be the linchpins to ensuring that all students succeed regardless of their special needs. Building strong co-teaching partnerships from the beginning is likely to translate into extraordinary inclusive classrooms where students can thrive within an atmosphere of productive team learning.

\section{References}

[1] Klinger, J.K, Vaughn, S., Hughes, S.T., Schumm, J.S., \& Elbaum, B (1998). Outcomes for students with and without learning disabilities in inclusive classrooms. Learning Disabilities Research \& Practice, 13, 153-161.

[2] Fontana, K.C. (2005). The effects of co-teaching on the achievement of eighth grade students with learning disabilities. The Journal of At-Risk Issues, 11(2), 17-23.

[3] Mainzer, L. (2010). Boundless Learning Foundations: A Review of the Literature on Co-Teaching. Columbia, MD: Center for Technology in Education, Johns Hopkins University.

[4] Caper, C.A. \& Frattura, Elise M. (2009). Meeting the Needs of Students of ALL Abilities: How Leaders Go Beyond Inclusion. Thousand Oaks, California: Corwin Press.

[5] Welch, M. (2000). Descriptive analysis of team teaching in two elementary classrooms; A formative experiment. Remedial and Special Education, 21(6). 366376.

[6] Magiera, K., \& Zigmond, N. (2005). Co-teaching in middle school classrooms under routine conditions: Does the instructional experience differ for students with disabilities in co-taught and solo-taught classes? Learning Disability Research \& Practice, 20(2), 79-85.

[7] Mastropieri, M. A., Scruggs, T. E., Graetz, J., Norland, J., Gardizi, W., \& McDuffie, K. (2005). Case studies in coteaching in the content areas: Successes, failures, and challenges. Intervention in School and Clinic, 40(5), 260270 .

[8] Buckley, C. Y. (2005). Establishing and maintaining collaborative relationships between regular and special education teachers in middle school social studies inclusive classrooms. In T. E. Scruggs \& M. A. Mastropieri (Eds.), Cognition and learning in diverse settings: Advances in learning and behavioral disabilities (Vol. 18, pp. 153198). San Diego, CA: Elsevier.

[9] Damore, S.J. \& Murray, C. (2009). Urban elementary school teachers' perspectives regarding collaborative teaching practices, Remedial and Special Education, 30(4), 234-244.

[10] McDuffie, K., Scruggs, T., \& Mastropieri, M. (2007). Co-Teaching in inclusive settings: Results of qualitative research from the United States, Canada, and Australia. In T. Scruggs \& M. Mastropieri (Eds.), Advances in learning and behavioral disabilities (Vol. 20, pp. 311-338). Oxford, UK: Elsevier.

[11] Scruggs, T.E., Mastropieri, M.A., \& McDufflie, K.A. (2007). Co-teaching in inclusive classrooms: A metasynthesis of qualitative research. Exceptional Children, 3, 392-416.

[12] Kohler-Evans, P.S. (2006). Co-teaching: How to make this marriage work in front of the kids. Education, 
$127,260-264$.

[13] McDuffie, K., Scruggs, T., \& Mastropieri, M. (2007). Co-Teaching in inclusive settings: Results of qualitative research from the United States, Canada, and Australia. In T. Scruggs \& M. Mastropieri (Eds.), Advances in learning and behavioral disabilities (Vol. 20, pp. 311-338). Oxford, UK: Elsevier.

[14] Mainzer, L. (2010). Boundless Learning Foundations: A Review of the Literature on Co-Teaching. Columbia, MD: Center for Technology in Education, Johns Hopkins University.

[15] Buckley, C. Y. (2005). Establishing and maintaining collaborative relationships between regular and special education teachers in middle school social studies inclusive classrooms. In T. E. Scruggs \& M. A. Mastropieri (Eds.), Cognition and learning in diverse settings: Advances in learning and behavioral disabilities (Vol. 18, pp. 153198). San Diego, CA: Elsevier.

[16] Mastropieri, M. A., Scruggs, T. E., Graetz, J., \& Connors, N. (2005). Inclusive practices in content area instruction: Addressing the challenges of co-teaching. In T.E. Scruggs \& M.A. Mastropieri (Eds.), Cognition and learning in diverse settings: Advances in learning and behavioral disabilities (Vol. 18, pp. 225-260). San Diego, $\mathrm{CA}$; Elsevier.

[17] Mastropieri, M. A., Scruggs, T. E., Graetz, J., \& Connors, N. (2005). Inclusive practices in content area instruction: Addressing the challenges of co-teaching. In T.E. Scruggs \& M.A. Mastropieri (Eds.), Cognition and learning in diverse settings: Advances in learning and behavioral disabilities (Vol. 18, pp. 225-260). San Diego, CA; Elsevier.

[18]. Katzenbach, J.R., \& Smith, D.K. (2005). The discipline of teams: What makes the difference between a team that performs and one that doesn't? Harvard Business Review, July-August, 2005, 162-171.

[19] Drucker, P. (1954). The practice of management. New York: Harper.

[20] Hang, Q. \& Rabren, K. (2009). An examination of coteaching: Perspectives and efficacy indicators. Remedial and Special Education, 30(5), 259-268. 